\title{
Study on the Ship Electric Propulsion System and Its Development
}

\author{
Hai-chun Niu ${ }^{1, a,{ }^{*}}$, Mei-lian Zhao ${ }^{1, b}$ and Fu-zhen Qin ${ }^{1, c}$ \\ ${ }^{1}$ Qingdao Huanghai University, Qingdao, Shandong, China

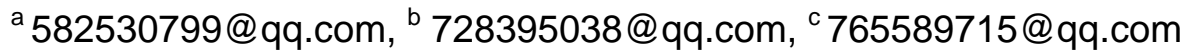

\begin{abstract}
In this paper, based on the advantages and composition of ship electric propulsion system, the authors focuses on the ship future development prospects. The present situation and future development trend of the ship electric propulsion system are expounded from three aspects: the development of new energy, the way of innovation promotion and the comprehensive power system.
\end{abstract}

Keywords: Ship, Electric propulsion, Development trend

\section{Introduction}

What kind of propulsion method of the ship used has been an important area of research for workers who are from Ship Science and Technology. The traditional method of driving the ship forward is to use the prime mover to drive the propeller through the shaft. And the ship's electric propulsion is driven by the prime mover to generate the generator, and the electric energy is supplied to the propulsion motor by the frequency converter, and the propeller is driven by the propulsion motor to push the ship forward. Electric propulsion has the advantages of high mobility, good safety and reliability, high degree of automation and good environmental protection effect, and is becoming the advancing way of the ship in the 21st century.

\section{Main advantages of Ship Electric Propulsion}

Ship electric propulsion compared with the traditional way of direct comparison of diesel engines, mainly has the following advantages:

(1) Electric propulsion eliminates the need for a large amount of space between the diesel engine and the propeller shafts and rudders, with a significant reduction in the total weight of the mechanical equipment, increased tank capacity and improved ship navigation economy.

(2) the power of a high degree of automation, control, convenient, flexible, able to cope with emergency situations, can effectively improve the ship's handling, mobility and safety and reliability.

(3) the prime mover can use the high-speed non-reversible thermal engine, improve the flexibility of choice, and can reduce the weight of equipment, thereby increasing the ship's payload.

(4) According to the working conditions selected into the grid of the generating units, so that each generator are working in a higher load state, to ensure a good combustion of diesel engines, saving fuel and reduce emissions. 


\section{Composition of Ship Electric Propulsion System}

At present, the world's use of electricity to promote the ship, can be divided into two categories: one is the electric propulsion and other engine propulsion combined with the propulsion approach, the other is the whole power to promote, that is, a total power supply to promote the motor and other Electrical equipment.

The ship electric propulsion device mainly includes generator, filter, frequency converter, propulsion motor, propeller and propulsion control system, as shown in Fig 1.

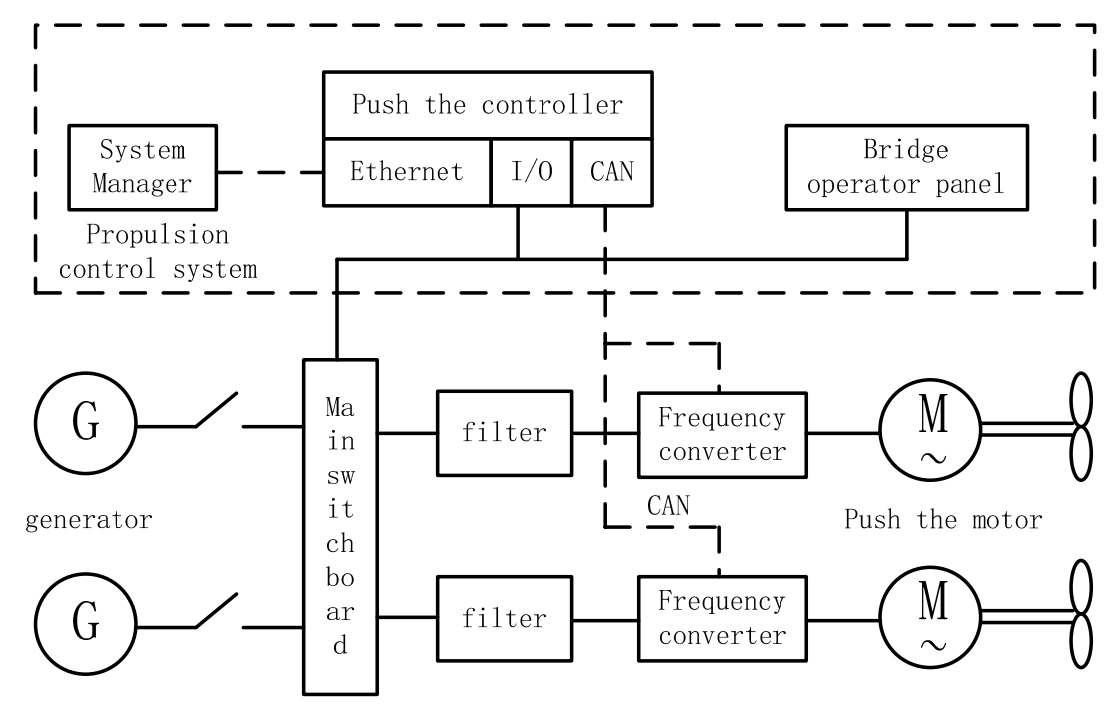

Figure 1 Ship Electric Propulsion System

The propulsion control system consists of a system manager, a propulsion controller and a bridge operator panel. Push the controller through the CAN bus on the remote control, to achieve the motor to start, speed, braking, security restrictions and fault alarm and other operations; system manager through the Ethernet to push the controller parameter values on-line tuning and modification, And at any time to monitor the entire ship electric propulsion system operating parameters and operating status.

\section{Development trend of ship electric propulsion}

The use of new energy

At present, the power source of electric propulsion ships is almost all diesel or gasoline. However, the diesel or petrol engine ships in the work of the exhaust emissions and oil and water leakage, the air and water will cause serious pollution; In addition, the global oil resources are also declining. Therefore, we must find renewable energy and how to use it before the oil resources are exhausted.

Fuel cell

The so-called fuel cell, is able to directly convert chemical energy into electrical power generation equipment. As long as the constant

Of the fuel cell in the reactor to add fuel and oxidants, you can get power, so you can improve the life of the ship. In addition, the fuel cell is not burned, the chemical energy can be converted directly into electricity, so the energy loss is small, no waste gas and noise pollution, environmental protection effect is good. Moreover, the fuel cell structure is 
compact, can reasonably use the effective space of the ship. These advantages will inevitably make fuel cells become one of the ship's power source.

wind, solar and wave energy

Wind energy, solar energy and wave energy are clean energy that can be fully utilized at sea. Rich in reserves and easy access. For example, you can design a rotary solar panel sail on a deck to convert solar or wind energy into electrical or propulsion; you can also design a telescopic propeller on a side to convert the wave energy into propulsion. Therefore, the full and efficient conversion of natural energy into electricity or ship propulsion is necessarily an important direction for ship power system research.

\section{Biodiesel}

Biodiesel is a kind of clean and recyclable liquid fuel for transportation, such as discarded animal and vegetable fats, non-edible grass / woody oil, etc. It has low cetane number, low toxicity, low sulfur, biodegradable, No aromatic hydrocarbons and other characteristics, can be directly replaced or with fossil diesel to reconcile the use of effective to improve the low sulfur diesel lubricity, is conducive to reducing the diesel engine exhaust particles, carbon monoxide, hydrocarbons, sulfides and other pollutants emissions.

As a potential alternative to fuels, biodiesel is gaining more and more attention for its good environmental and economic value. China's vast land area, animal and plant resources rich, and is a large energy-consuming countries, so to develop and promote bio-diesel on the sustainable development of the economy, promote energy substitution, reduce environmental pollution is of great significance. It can be seen that the development of marine power plant which can meet the requirements of the ship and can transform the biomass high quality and high efficiency into electric energy will be an important direction for the future development of the ship's electric propulsion system.

4.2 Innovative Promotion Way

(1) pod type electric propulsion system

The pod-type electric propulsion system is an all-in-one device that mounts the motor in a $360^{\circ}$ rotating pod, and the propeller is directly connected to the motor shaft and is a popular way forward. The system's handling and propulsion efficiency is very good, and because of the need for shafting, rudder and side pushers, saving a lot of space, reducing the ship's own weight, reducing noise and vibration, better motor performance, installation and more convenient.

(2) superconducting electromagnetic propulsion technology

Superconducting electromagnetic propulsion technology is the use of fixed on the ship's superconducting coil magnetic field and the role of water in the sea, so that the conductive sea water by the Lorentz force in the flow, resulting in the reaction to promote the ship forward. The technology is the direct conversion of electric energy into fluid kinetic energy, jet propulsion to replace the traditional propeller propulsion, to overcome the transmission machinery power limit, but also to overcome the propeller high-speed rotation of the air cannon, it has a low noise and security characteristics, In the special ship propulsion application has great value.

(3) water jet propulsion system

Water jet propulsion is a new type of special power plant, unlike the common propeller propulsion approach, the propulsion of the water jet propulsion is achieved by pushing the reaction force of the water jet from the pump and passing the valve To change the direction of 
the water, so that the ship forward, turn or back.

Water jet propulsion equipment Low noise, low vibration, shallow draft, simple transmission mechanism, small resistance of accessories, good protection performance, and excellent high-speed maneuverability, the lateral force generated during rotation can reduce the radius of rotation. But when the ship speed is less than $20 \mathrm{kn}$, the water jet propulsion efficiency is lower than the propeller. As the weight of the water in the pipeline increases, the displacement of the aircraft increases and the efficiency decreases. In aquatic plants or debris more water, imports are prone to clogging and affect the speed of the ship.

The above-mentioned superconducting electromagnetic propulsion technology and water jet propulsion technology are the propulsion methods that are now considered to have development potential in the field of ship electric propulsion systems, but they have advantages and disadvantages. In the future, how to overcome the shortcomings and better To play their advantages or to develop a more effective propeller is another direction for the development of electricity.

Integrated all-electric propulsion system (IPS)

Integrated power propulsion system is to promote the use of electricity and electricity combined into one, the system uses modular structure and regional distribution, mainly by the monitoring sub-system, regional distribution system, power generation subsystem and daily distribution points System Components. IPS system structure shown in Figure 2.

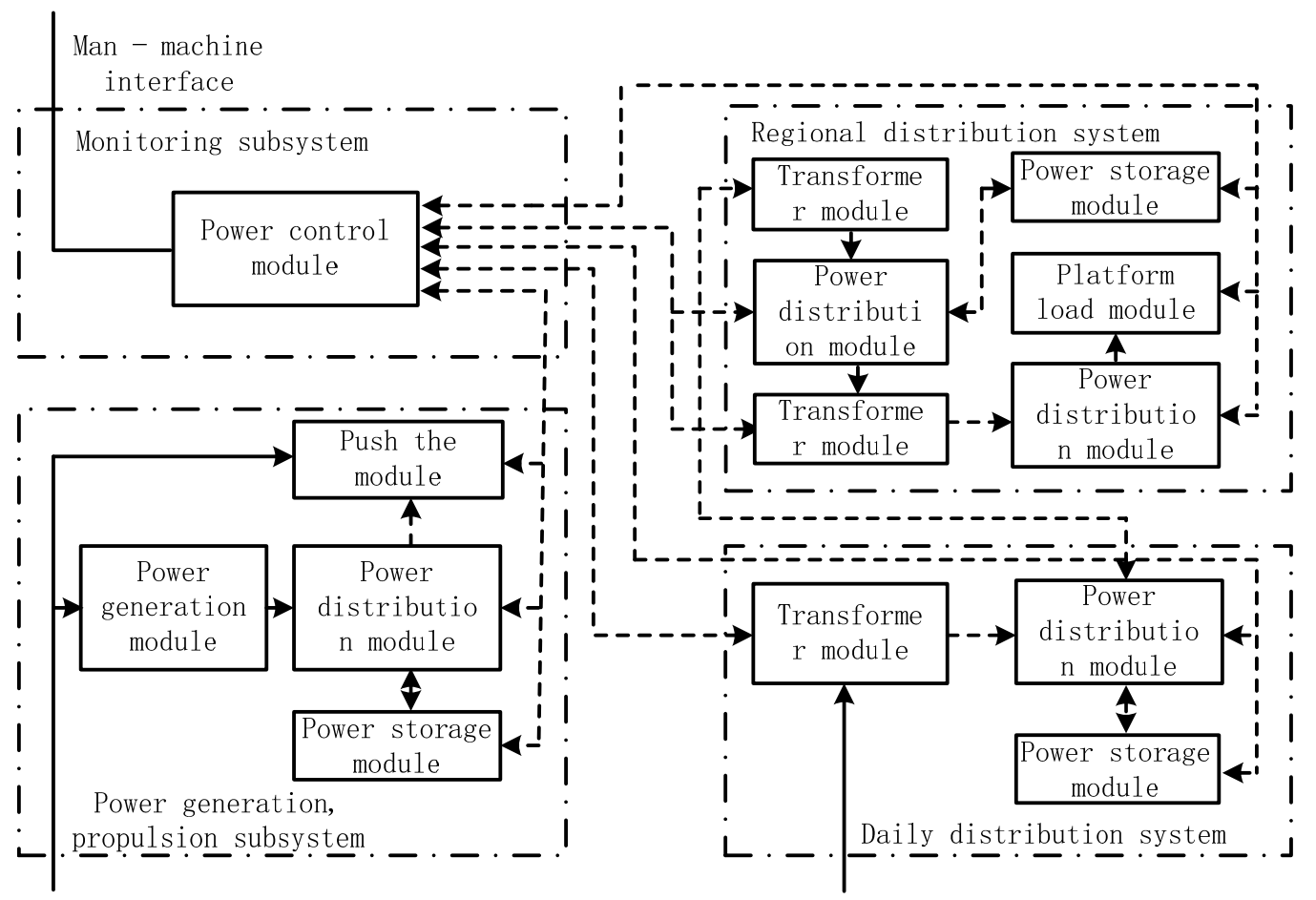

Figure 2 IPS System

IPS system uses modular design, including power generation, substation, power distribution, power storage, power control and a series of modules, to meet the requirements of different ships. As the integrated all-electric propulsion system design involves a number of disciplines, a number of areas, is a comprehensive use of a variety of technologies. Therefore, it is necessary to carry out comprehensive, comprehensive and systematic research on the integration of the modules and the modules between the modules, so that the modules are running well and coordinated with each other to ensure the best performance of the IPS 
system. Modular design not only makes the ship manufacturing process standardized, procedural, but also the ship inspection and other related work becomes standardized, specific and easy.

\section{Conclusion}

Ship electric propulsion is the result of the rapid development of modern power electronic technology, exchange speed control technology and motor technology. Although the initial investment in the advancement of the ship's electricity, maintenance and management is difficult, but through the late navigation of energy saving, increase the capacity to make up for. And with the progress of science and technology, the initial investment in electricity to promote the inevitable reduction. In the future, although the power propulsion can not completely replace the other ship propulsion, but it will become more and more proportion. Electricity propulsion in the future mainly through the use of new energy, innovative ways to promote and improve the IPS to get a broad space for development, which brings huge economic and social benefits. The 21st century will usher in the development of the ship to promote the golden age of electricity.

\section{References:}

[1] Wang Ying. On the ship power propulsion system development status and trends [J]. Science and Technology Information, 2010, (35): 102.

[2] Chen Xinyi, Yang Ye. Overview of ship power propulsion technology development [J]. China Water Transport, 2008,8 (8): 48-49.

[3] Yu Wensheng. Ship power to promote the future direction of development [J]. World Shipping, 2007,30 (3): 43-45.

[4] Li Nan. Modern ship electric propulsion system development [J]. China Water Transport, 2009,9 (1): 1-2.

[5] Shen Aidi, Chu Jianxin, Kang Wei.Design of Electric Propulsion System for Inland River Ship [J]. Journal of Shanghai Maritime University, 2009,30 (2): 20-24.

[6] Ji Mingli. AC variable frequency speed control technology in the ship electric propulsion system application [J]. Manufacturing automation, 2010,32 (9): 123-125.

[7] Zhang Wei, Chen Hui. Ship propulsion technology for the 21st century [J]. Transportation Science and Technology, 2003, (2): 48-50.

[8] Tang Tianhao. Development and application of new energy and power electronics in ship electric propulsion [J]. Journal of Shanghai Maritime University, 2004,25 (1): 19-24. 